\title{
Gambaran Premenstrual Syndrome pada Remaja Periode Akhir di Fakultas Kedokteran Universitas Sam Ratulangi
}

\author{
Charisma Lumingkewas, ${ }^{1}$ Eddy Suparman, ${ }^{2}$ Suzanna P. Mongan ${ }^{2}$
}

${ }^{1}$ Program Studi Pendidikan Dokter Fakultas Kedokteran Universitas Sam Ratulangi, Manado, Sulawesi Utara, Indonesia

${ }^{2}$ Bagian Ilmu Kebidanan dan Kandungan Fakultas Kedokteran Universitas Sam Ratulangi, Manado, Sulawesi Utara, Indonesia

Email: 17011101035@ student.unsrat.ac.id

\begin{abstract}
Premenstrual syndrome (PMS) is the most common untreated disorder and a public health problem among women of reproductive age, which adversely affects mental well-being, quality of life, and academic achievement. This study was aimed to determine the premenstrual syndrome signs and symptoms most experienced by late adolescents. This was a descriptive and survey study using questionnaire distributed through google form to 142 female students from first and third semester of Faculty of Medicine Sam Ratulangi University academic year 2020/2021. The results showed that the most common type of PMS symptoms was psychological symptoms found in 136 respondents $(95.8 \%)$; the most common behavioral symptom was fatigue in 93 respondents (65.5\%), the most common physical symptom was acne in 122 respondents (85.9\%); and the most psychological symptom was mood swing in 125 respondents $(88 \%)$. In conclusion, the most common premenstrual syndrome symptom found in late adolescent at the Faculty of Medicine Sam Ratulangi University according to the type of symptom was psychological symptom.
\end{abstract}

Keywords: premenstrual syndrome, adolescent

\begin{abstract}
Abstrak: Premenstrual syndrome (PMS) merupakan kelainan umum yang tidak diobati dan masalah kesehatan masyarakat di kalangan wanita usia reproduksi, yang berdampak buruk pada kesejahteraan mental, kualitas hidup dan prestasi akademik. Penelitian ini bertujuan untuk mengetahui tanda dan gejala PMS yang paling banyak dialami remaja periode akhir. Penelitian ini menggunakan metode survei deskriptif dengan alat kuesioner yang dibagikan melalui google form pada 142 mahasiswi semester 1 dan 3 Fakultas Kedokteran Universitas Sam Ratulangi tahun ajaran 2020/2021. Hasil penelitian mendapatkan jenis gejala PMS yang paling banyak dialami ialah gejala psikologis pada 136 responden $(95,8 \%)$, gejala perilaku yang paling banyak dialami ialah kelelahan pada 93 responden $(65,5 \%)$, gejala fisik yang paling banyak dialami ialah muncul jerawat pada 122 responden $(85,9)$, dan gejala psikologis yang paling banyak dialami ialah mood swing pada 125 responden (88\%). Simpulan penelitian ini ialah gambaran PMS pada remaja periode akhir di Fakultas Kedokteran Universitas Sam Ratulangi yang paling banyak dialami menurut jenis gejala ialah gejala psikologis.
\end{abstract}

Kata kunci: premenstrual syndrome, remaja

\section{PENDAHULUAN}

Remaja merupakan masa peralihan dari masa anak-anak ke dewasa. Ada pula yang menyebutkan sebagai masa persiapan untuk menjadi lebih matang dalam kehidupan dan sebagainya. ${ }^{1}$ Menurut World Health Orga- nization (WHO), remaja adalah penduduk yang berusia 10-19 tahun. Menurut Peraturan Menteri Kesehatan RI Nomor 25 Tahun 2014, remaja adalah penduduk yang berusia 10-18 tahun dan menurut Badan Kependudukan dan Keluarga Berencana 
(BKKBN) rentang usia remaja adalah 10-24 tahun dan belum menikah. Masa remaja merupakan periode terjadinya pertumbuhan dan perkembangan baik secara fisik, psikologis maupun intelektual. ${ }^{2}$ Perubahan dari masa kanak-kanak menuju masa dewasa atau sering dikenal dengan istilah masa pubertas ditandai dengan datangnya menstruasi pada wanita. $^{3}$ Menstruasi adalah perdarahan periodik dan siklik dari uterus dan diserta pelepasan endometrium. ${ }^{4}$ Masalah yang timbul saat menstruasi merupakan masalah ginekologi yang sering dikeluhkan remaja. ${ }^{5}$ Gangguan menstruasi menjadi permasalahan utama pada wanita di Indonesia. ${ }^{6}$ Salah satu gangguan yang berhubungan dengan menstruasi ialah premenstrual syndrome (PMS). ${ }^{5}$

Premenstrual syndrome merupakan salah satu penyakit ginekologi yang paling umum. Lebih dari separuh wanita tidak terdiagnosis dan tidak terkelola dengan baik. ${ }^{7}$ PMS didefinisikan sebagai sekelompok gejala ringan hingga sedang, fisik dan perilaku, dan dapat mengganggu pekerjaan dan hubungan pribadi. ${ }^{8}$ Kumpulan gejala yang dirasakan wanita menjelang menstruasi tersebut muncul 7-10 hari sebelum menstruasi. Gejala-gejala yang dialami oleh wanita itu seperti gejala perilaku, fisik dan psikologis. $^{9}$

Gejala bervariasi dari wanita ke wanita, dan lebih dari 150 gejala telah dikaitkan dengan gangguan tersebut. ${ }^{10}$ PMS merupakan kelainan umum yang tidak diobati dan masalah kesehatan masyarakat di kalangan wanita usia reproduksi, yang berdampak buruk pada kesejahteraan mental, kualitas hidup dan prestasi akademik. ${ }^{11}$ Bentuk PMS yang dialami wanita sangat bervariasi antara satu dengan yang lain. ${ }^{12}$ Morbiditas PMS terkait dengan tingkat keparahan, kronisitas, dan tekanan yang diakibatkannya yang memengaruhi pekerjaan, hubungan pribadi, atau aktivitas sehari-hari. Penelitian secara konsisten menunjukkan bahwa gangguan atau kesusahan terbesar akibat PMS ada dalam hubungan dengan pasangan atau anak-anak dan efektivitas kerja. ${ }^{13}$

Pada sebuah penelitian di India, Raval et $\mathrm{al}^{` 14}$ mendapatkan prevalensi PMS yaitu
$18.4 \%$. Buddhabunyakan et $\mathrm{al}^{10}$ mendapatkan bahwa 86 (29,8\%) dari 289 siswi SMA di Thailand mengalami PMS. Dalam penelitiannya, terdapat prevalensi gejala PMS yaitu nyeri payudara $(74,4 \%)$ dan ledakan amarah $(97,7 \%)$. Berdasarkan studi pada remaja putri di Turki ditemukan prevalensi PMS yaitu $61,4 \%$. Pada siswa sekolah menengah Jepang prevalensi PMS ditemukan $64,6 \%$. Pada wanita usia subur Spanyol dengan prevalensi $73,7 \%$, dan pada wanita mahasiswa sarjana dari University of Calabar, Nigeria dengan prevalensi 85,5\%. ${ }^{11}$

Di Indonesia, Ilmi et $\mathrm{al}^{9}$ meneliti faktor dominan PMS pada mahasiswi Fakultas Kesehatan Masyarakat dan Departemen Arsitektur Fakultas Teknik di Universitas Indonesia dan gejala PMS paling berat yang dirasakan responden ialah nyeri perut $(26,9 \%)$, sakit panggul dan nyeri sendi $(24,6 \%)$, sedih dan tidak bersemangat (20\%).

Berdasarkan data yang diperoleh di atas bahwa frekuensi PMS pada remaja masih cukup tinggi dan cukup memengaruhi aktivitas mereka, maka penulis tertarik untuk meneliti gambaran PMS pada remaja periode akhir dengan mengambil mahasiwi semester 1 dan 3 di Fakultas Kedokteran Universitas Sam Ratulangi tahun akademik 2020/2021 sebagai responden. Alasan penulis memilih responden tersebut karena penulis menganggap masih banyak mahasiswi yang tergolong dalam remaja periode akhir mengalami dan mengeluhkan PMS sampai memengaruhi aktivitas mereka terlebih khusus saat berkuliah sehingga diharapkan mahasiwi dapat mewakili remaja periode akhir dan data yang diperoleh penulis akan lebih akurat.

\section{METODE PENELITIAN}

Penelitian dilakukan secara daring dengan menggunakan google form. Jenis penelitian ialah deskriptif kuantitatif dan menggunakan metode survei dengan alat kuesioner. Sampel dalam penelitian ini ialah mahasiswi semester 1 dan 3 Fakultas Kedokteran Universitas Sam Ratulangi Manado tahun akademik 2020-2021 yang berjumlah 142 orang. Teknik pengambilan sampel ialah non probability sampling 
dengan jenis purposive sampling. Jumlah sampel diambil dengan menggunakan rumus Slovin. Variabel yang digunakan dalam penelitian ini ialah variabel tunggal yaitu tanda dan gejala PMS.

\section{HASIL PENELITIAN}

Penelitian ini dilakukan pada 142 mahasiswi semester 1 dan 3 Fakultas Kedokteran Universitas Sam Ratulangi pada bulan September sampai November 2020.

Tabel 1 memperlihatkan usia rersponden terbanyak ialah 18 tahun yaitu sebanyak 94 orang $(66,2 \%)$. Responden yang berusia 19 tahun berjumlah 48 orang $(33,8 \%)$.
Tabel 2 memperlihatkan bahwa jenis gejala PMS yang paling banyak dialami ialah gejala psikologis yaitu sebanyak 136 orang $(95,8 \%)$.

Tabel 3 memperlihatkan bahwa gejala perilaku PMS yang paling banyak dialami ialah kelelahan yaitu sebanyak 93 orang $(65,5 \%)$.

Tabel 1. Karakteristik usia responden

\begin{tabular}{ccc}
\hline $\begin{array}{c}\text { Usia } \\
\text { (tahun) }\end{array}$ & Jumlah & $\%$ \\
\hline 18 & 94 & 66,2 \\
19 & 48 & 33,8 \\
Total & 142 & $100 \%$ \\
\hline
\end{tabular}

Tabel 2. Distribusi jenis gejala PMS

\begin{tabular}{lcccc}
\hline \multicolumn{1}{c}{ PMS } & \multicolumn{2}{c}{ Ya } & \multicolumn{2}{c}{ Tidak } \\
& Jumlah & $\%$ & Jumlah & $\%$ \\
\hline Gejala perilaku & 116 & 81,7 & 26 & 18,3 \\
Gejala fisik & 131 & 92,3 & 11 & 7,7 \\
Gejala psikologis & 136 & 95,8 & 6 & 4,2 \\
\hline
\end{tabular}

Tabel 3. Distribusi gejala perilaku PMS

\begin{tabular}{lcccc}
\hline \multirow{2}{*}{ Gejala perilaku } & \multicolumn{2}{c}{ Ya } & \multicolumn{2}{c}{ Tidak } \\
& Jumlah & $\%$ & Jumlah & $\%$ \\
\hline Kelelahan & 93 & 65,5 & 49 & 34,5 \\
Insomnia & 36 & 25,4 & 106 & 74,6 \\
Pusing & 65 & 45,8 & 77 & 54,2 \\
Mengidam makanan atau & 80 & 56,3 & 62 & 43,7 \\
makan berlebihan & 71 & 50 & 71 & 50 \\
Konsentrasi buruk & 39 & 27,5 & 103 & 72,5 \\
Menarik diri dari pergaulan & 51 & 35,9 & 91 & 64,1 \\
Menangis & & & & \\
\hline
\end{tabular}

Tabel 4. Distribusi gejala fisik PMS

\begin{tabular}{lcccc}
\hline \multicolumn{1}{c}{ Gejala fisik } & \multicolumn{3}{c}{ Ya } & \multicolumn{2}{c}{ Tidak } \\
& Jumlah & $\%$ & Jumlah & $\%$ \\
\hline Sakit kepala & 80 & 56,3 & 62 & 43,77 \\
Muncul jerawat & 122 & 85,9 & 20 & 14,1 \\
Pembengkakan atau nyeri payudara & 56 & 39,4 & 86 & 60,6 \\
Nyeri punggung & 58 & 40,8 & 84 & 59,2 \\
Nyeri perut atau kembung & 89 & 62,7 & 53 & 37,3 \\
Nyeri otot dan sendi & 38 & 26,8 & 104 & 73,2 \\
Berat badan bertambah & 37 & 26,1 & 105 & 73,9 \\
Pembengkakan ekstremitas & 8 & 5,6 & 134 & 94,4 \\
\hline
\end{tabular}


Tabel 4 memperlihatkan bahwa gejala fisik PMS yang paling banyak dialami ialah muncul jerawat yaitu sebanyak 122 orang $(85,9 \%)$.

Tabel 5 memperlihatkan bahwa gejala psikologis PMS yang paling banyak dialami ialah mood swing yaitu sebanyak 125 orang $(88 \%)$.

\section{BAHASAN}

Hasil penelitian pada jenis gejala PMS sesuai dengan penelitian yang dilakukan Heryaningtyas et al ${ }^{15}$ pada 124 responden didapatkan bahwa gejala PMS yang paling banyak dialami adalah gejala psikologis. Pada penelitian tersebut gejala psikologis dialami oleh 92 orang $(74,2 \%)$.

Gejala psikologis merupakan kunci utama pada gejala PMS. Menurut beberapa peneliti, faktor utama yang memengaruhi gejala psikologis ialah adanya ketidakseimbangan antara kadar hormon estrogen dan progesteron dalam tubuh sebelum memasuki fase menstruasi itu berlangsung. Hormon estrogen dan progestreron tersebut yang akan memengaruhi kadar serotonin dalam otak, kadar serotonin secara langsung memengaruhi suasana hati sehingga terjadi perubahan psikologis, fisik dan perilaku. ${ }^{15}$

Gejala perilaku PMS yang paling banyak dialami ialah kelelahan Wanita yang sedang mengalami PMS akan terjadi perubahan hormon estrogen dan progesteron. Saat itu juga terjadi ketidakseimbangan hormon estrogen dan hormon progesteron pada wanita yang sedang mengalami PMS, yaitu kadar progesteron menurun dan kadar esterogen meningkat. Perubahan hormon tersebut yang akan berpengaruh terhadap penurunan sintesis serotonin. Kadar serotonin itu sendiri akan berpengaruh terhadap suasana hati dan perilaku. Kadar serotonin yang berubah-ubah selama siklus menstruasi, dan aktivitas serotonin sendiri berhubungan dengan kelelahan. Selain itu juga kadar serotonin yang berubah-ubah selama siklus menstruasi berhubungan dengan gejala depresi, kecemasan dan agresif. ${ }^{16}$

Hasil penelitian ini sesuai dengan penelitian Heryaningtyas et al ${ }^{15}$ bahwa gejala fisik PMS yang paling banyak dialami ialah timbulnya jerawat yaitu sebanyak 100 orang $(80,6 \%)$ yang mengeluhkan timbulnya jerawat. Wahyuni et $\mathrm{al}^{17}$ mendapatkan 84 orang $(75,7 \%)$ yang mengeluhkan timbulnya jerawat. Faktor hormonal cukup berperan dalam timbulnya gejala saat menjelang haid. Perubahan hormon dapat menyebabkan kelenjar sebasea memroduksi sebum yang lebih banyak dari biasanya yang dapat menyumbat pori-pori sehingga bisa menimbulkan jerawat. ${ }^{15}$

Untuk gejala psikologis yang paling banyak dialami sesuai dengan penelitian yang dilakukan Heryaningtyas et al. ${ }^{15}$ yang mendapatkan 115 orang $(92,7 \%)$ mengalami mood swing. Hal tersebut terjadi oleh karna perubahan pada hormon estrogen akan memengaruhi hormon serotonin. Kadar serotonin akan berpengaruh terhadap suasana hati. Berkurangnya hormon serotonin juga akan menimbulkan efek depresi, kemarahan, agresivitas, iritabilitas dan perasaan lemah. ${ }^{16}$

Tabel 5. Distribusi gejala psikologis PMS

\begin{tabular}{lcccc}
\hline \multicolumn{2}{c}{ Gejala psikologis } & Ya & \multicolumn{2}{c}{ Tidak } \\
& Jumlah & $\%$ & Jumlah & $\%$ \\
\hline Mood swing & 125 & 88 & 17 & 12 \\
Marah & 111 & 78,2 & 31 & 21,8 \\
Perasaan depresi & 83 & 58,5 & 59 & 41,5 \\
Kecemasan & 72 & 50,7 & 70 & 49,3 \\
Kebingungan & 49 & 34,5 & 93 & 65,5 \\
Pelupa & 68 & 47,9 & 74 & 52,1 \\
Kegelisahan & 74 & 52,1 & 68 & 47,9 \\
\hline
\end{tabular}


Bahkan beberapa wanita mengalami depresi ringan sampai sedang saat sebelum haid. Gejala ini timbul akibat ketidakseimbangan hormon estrogen dan progesteron yaitu hormon estrogen terlalu tinggi dibandingkan hormon progesteron. Pemberian hormon progesteron kadang dilakukan untuk mengurangi gejala tetapi beberapa peneliti menyatakan bahwa pada penderita PMS bisa terjadi kekurangan vitamin B6 dan magnesium. Penderita PMS tipe ini sebaiknya mengonsumsi makanan berserat dan membatasi atau mengurangi minum kopi. ${ }^{18}$

Klasifikasi masa remaja yang terbagi menjadi tiga memberikan pengaruh yang berbeda terhadap bentuk emosi menjelang menstruasi. Perbedaan bentuk emosi yang muncul pada remaja akhir berupa emosi mudah murah, perasaan sedih dan cemas cenderung menurun tetapi suasana hati yang berubah-ubah menunjukkan mengalami peningkatan. Perbedaan tersebut dipengaruhi oleh sistem kepribadian yang tidak sama pada setiap individu yang dipengaruhi oleh perkembangan ilmu pengetahuan, informasi, pengaruh media massa, keluarga, sekolah, teman sebaya, budaya, agama, serta nilai dan norma masyarakat. ${ }^{19}$

\section{SIMPULAN}

Gambaran PMS pada remaja periode akhir di Fakultas Kedokteran Universitas Sam Ratulangi yang paling banyak dialami menurut jenis ialah gejala psikologis PMS. Gejala perilaku, fisik dan psikologis yang paling banyak dialami ialah kelelahan, muncul jerawat dan mood swing.

Diharapkan agar remaja periode akhir dapat meningkatkan pengetahuan mengenai PMS sehingga dapat mengetahui cara mengurangi dan mengatasi gejala yang dialami dengan tepat. Untuk peneliti lanjut agar dapat meneliti mengenai gejala PMS tidak hanya pada remaja periode akhir tapi pada semua kategori remaja, serta hubungan penyebab atau faktor risiko dengan PMS.

\section{Ucapan Terima Kasih}

Penulis mengucapkan terima kasih kepada semua pihak yang turut serta me- nyumbang usul dan saran dalam penulisan artikel ini.

\section{Konflik Kepentingan}

Penulis menyatakan tidak terdapat konflik kepentingan dalam studi ini.

\section{DAFTAR PUSTAKA}

1. Repi AA, Santoso JE. Aku, Remaja yang Positif. Jakarta: Elex Media Komputindo, 2018; p. 3.

2. Kementerian Kesehatan RI. Infodatin Reproduksi Remaja-Ed.pdf. Situasi Kesehatan Reproduksi Remaja, 2017; p. 1-8.

3. Narasiang B, Wantania J, Mewengkang M. Gambaran pengetahuan siswi SMP tentang kehamilan remaja. e-CliniC. 2015;3(1):1-4.

4. Pratama FY. Latihan abdominal stretching menurunkan tingkat nyeri haid remaja putri di SMAN 3 Brebes. 2018 [cited 2020 Aug 27]; Available from: http://repository.unimus.ac.id/1690/

5. Tantina T. Analisis karakteristik hubungan pengetahuan dan sikap dengan tindakan mengatasi premensruasi sindrom. J Penelit Keperawatan Med. 2019; 1(2): 17.

6. Pratiwi RA. Gambaran pola konsumsi vitamin C, B1, dan B6 pada siswi premenstrual syndrome (PMS) di MAN 1 Semarang [Internet]. Universitas Muhammadiyah Semarang; 2018 [cited 2020 Aug 28]. Available from: http://repository. unimus.ac.id/id/eprint/2607

7. Kellerman RD. Conn's Current Therapy 2020 [Internet]. Elsevier; 2020 [cited 2020 Aug 27]. p. 1171-4. Available from: https://www.clinicalkey.com/\#!/content /book/3-s2.0-B978032371184500286 $\mathrm{X}$ ? scroll To $=\% 23 \mathrm{hl} 0000210$

8. Buddhabunyakan N, Kaewrudee S, Chongsomchai C, Soontrapa S, Somboonporn W, Sothornwit J. Premenstrual syndrome (PMS) among high school students. Int J Womens Health. 2017;9:501-5.

9. Ilmi AF, Utari DM. Faktor dominan premenstrual syndrome pada mahasiswi (Studi pada mahasiswi Fakultas Kesehatan Masyarakat dan Departemen Arsitektur Fakultas Teknik, Universitas Indonesia). Media Gizi Mikro Indones. 2018;10(1):39-50.

10. Raval CM, Panchal BN, Tiwari DS, Vala AU, Bhatt RB. Prevalence of premenstrual 
syndrome and premenstrual dysphoric disorder among college students of Bhavnagar, Gujarat. Indian J Psychiatry. 2016;58(2):164-70.

11. Ranjbaran M, Samani RO, Almasi-Hashiani A, Matourypour P, Moini A. Prevalence of premenstrual syndrome in Iran: A systematic review and meta-analysis. Int J Reprod Biomed. 2017;15(11):67986.

12. Listiana EL. Hubungan sindrom pramenstruasi dengan kontrol diri mahasiswi Fakultas Dakwah dan Komunikasi UIN Walisongo Semarang (tinjauan bimbingan konseling Islam) [Internet]. 2016 [cited 2020 Aug 27]. Available from: http://eprints.walisongo.ac.id/id/eprint/ 6447

13. Ikawati Z. Resep Hidup Sehat. Yogyakarta. Ranggabumi NA, editor. Yogyakarta: Kanisius; 2010.

14. Chin LN, Nambiar S. Management of premenstrual syndrome. Obstet Gynaecol Reprod Med. 2017;27:1-6.

15. Heryaningtyas F, Putra I, Sudiman J. Karakteristik premenstrual syndrome pada mahasiswi Program Studi Pendidikan Dokter angkatan 2017 di Fakultas Kedokteran Universitas Udayana. EJurnal Med Udayana. 2020;9(5):58-61.
Available from: https://ojs.unud.ac.id/ index.php/eum/article/view/61940

16. Zulfadriawan Z. Sistem pakar diagnosa premenstrual syndrome dengan metode Bayes [Internet]. Universitas Mercu Buana Yogyakarta; 2019. Available from: http://eprints.mercubuana-yogya. ac.id/id/eprint/4826

17. Wahyuni L, Hidayati NF. Tipe Dan Cara Mengatasi Pre Menstruasi Sindrom Pada Mahasiswi Kebidanan Unmuh Surabaya. J UM Surabaya. 2016. [cited 2020 Aug 27]. Available from: https://adoc.pub/tipe-dan-caramengatasi-pre-menstruasi-sindrompada-mahasisw.html

18. Puspadewi M. Dinamika emosi pada remaja yang mengalami premenstrual syndrome (PMS) [Internet]. Universitas Muhammadiyah Surakarta; 2012. Available from: http://eprints.ums.ac.id/ id/eprint $/ 21835$

19. Alvionita F. Hubungan pola makan dengan premenstrual syndrome pada mahasiswi S1 Pendidikan Bidan Fakultas Kedokteran Universitas Airlangga [Internet]. Universitas Airlangga; 2016. Available from: http://repository.unair. ac.id/id/eprint/54282. 